\title{
Age-related differences in response to ethanol in the rat
}

\author{
ERNEST L. ABEL and JAMES L. YORK \\ Research Institute on Alcoholism, 1021 Main Street, Buffalo, New York 14203
}

\begin{abstract}
Female rats, aged 2-3, 11-12, and 18-20 months were tested for their responsiveness to ethanol. The duration of ethanol hypnosis $(4 \mathrm{~g} / \mathrm{kg}$, IP) was greatest in old rats, but blood alcohol levels at time of awakening were lowest in older, compared with younger animals, suggesting a greater responsiveness of brain tissues to the hypnotic effects of ethanol in older rats or, alternatively, a more rapid development of central acute tolerance in younger subjects. Lower doses of ethanol $(.75-1.5 \mathrm{~g} / \mathrm{kg})$ were observed to produce greater hypothermia and impairment of motor performance in older animals. Although blood alcohol levels were higher in older animals following the injection $(1 \mathrm{~g} / \mathrm{kg}$, IP) of ethanol, there was no agerelated effect on rate of ethanol disappearance. Doses of ethanol that produced comparable blood levels in old $(1.0 \mathrm{~g} / \mathrm{kg})$ and young $(1.5 \mathrm{~g} / \mathrm{kg})$ animals also produced a similar degree of motor impairment. Thus, the greater effects produced by moderate doses of ethanol (around $1.0 \mathrm{~g} / \mathrm{kg}$ ) in older rats can be attributed to the higher peak drug levels achieved in those animals. Differential responses to hypnotic doses of ethanol may involve, additionally, a greater responsiveness of brain tissue to that drug in older animals.
\end{abstract}

Several studies have indicated that alcoholism is a significant health problem among the elderly (see reviews by Petersen \& Whittington, 1977; Schuckit \& Pastor, 1978). Although the overall incidence of heavy alcohol consumption among the elderly (60 years and over) may be less than that for the general population (e.g., Barnes \& Russell, 1977; Cahalan \& Cisin, 1968), psychiatric disorders in elderly individuals are often found to be associated with high levels of alcohol intake (Epstein, Mills, \& Simon, 1970; Schuckit \& Miller, 1976; Zimberg, 1974).

While personal and social changes associated with aging may impose unique stresses which encourage alcohol usage, it is also possible that age-related physiological changes may alter the reactions of some elderly individuals to the effects of alcohol. Only a paucity of studies to date have addressed this issue. For example, alcohol has been reported to have a greater inhibitory effect on spontaneous motor activity (Samorajski, Strong, \& Sun, 1977) and to be more toxic in older animals (Abel, 1978; Wiberg, Trenholm, \& Coldwell, 1970). Sun and Samorajski (1975) have reported the action of alcohol on membrane-bound synaptosomal $\left(\mathrm{Na}^{+}-\mathrm{K}^{+}\right)$ATPase activity in the brain to be greater in old rats as compared to young animals, suggesting a possible mechanism by which alcohol may affect aged animals more than young subjects.

We thank R. Lahcen, R. Eddy, and D. Boyer for technical assistance, D. DeStaffan, R. Grotte, and D. Nirelli for the preparation of illustrations and manuscript, and Dr. H. B. Greizerstein for blood ethanol determinations. This work was supported in part by Grant HRC 1342 from the New York State Health Planning Commission and Grant 5 R01 AA02689-02 from NIAAA.
The present study was designed to provide more information concerning the relative impairment produced by ethanol in rats of different ages. To this end, the effects of moderate doses of ethanol (.75$1.5 \mathrm{~g} / \mathrm{kg}$ ) on motor performance and temperature regulation and of hypnotic doses $(4.0 \mathrm{~g} / \mathrm{kg})$ were evaluated. A comparison of the blood levels of alcohol achieved in the different age groups allowed conclusions to be drawn regarding the role of drug disposition in the effects observed.

\section{METHODS}

\section{Subjects}

The subjects were female Sprague-Dawley rats obtained from the Carworth Division of Charles River (Wilmington, Mass.). The animals were of three different ages. Group Y (young, virgin) were 2-3 months of age; Group $M$ (middle, retired breeders) animals were 11-12 months of age; Group $O$ (old, retired breeders) animals were 18-20 months of age. The animals were housed individually in Plexiglas cages with beddings of wood shavings and were allowed continuous access to food (Teklad $4 \%$ rat and mouse diet) and water. The supplier reports the mean life span of rats under these conditions to be 28-29 months.

\section{Procedure}

Ethanol-induced hypnosis. Twelve animals per group were injected (IP) with ethanol $(4.0 \mathrm{~g} / \mathrm{kg}, 20 \% \mathrm{w} / \mathrm{v})$. The time from injection until loss of righting reflex was considered time of onset of action, and the time from loss until recovery of the righting response (animal righted itself twice within $15 \mathrm{sec}$ ) constituted duration of ethanol hypnosis.

At the time of recovery of the righting reflex, tail-tip samples of blood were taken. The samples were deproteinized with $\mathrm{ZnSO}_{4}$ and $\mathrm{Ba}(\mathrm{OH})_{2}$, propanol $(25 \mu \mathrm{l})$ was added as an internal standard, and the concentration of ethanol in the sample was determined by gas chromatography by the method of Greizerstein and Smith (1973).

Blood ethanol levels and disappearance. Ten animals per group were injected (IP) with $1 \mathrm{~g} / \mathrm{kg}$ of ethanol $(10 \% \mathrm{w} / \mathrm{v})$ and tailtip blood samples were obtained at $25,60,90,120$, and $180 \mathrm{~min}$ 
after injection. Blood samples were treated and analyzed by gas chromatography (see above). Comparisons of blood ethanol levels among different groups of rats were made by means of analyses of variance for repeated measures. Rate of disappearance was determined by calculating the slope for blood ethanol disappearance from the point of peak blood ethanol concentration.

Ethanol impairment of motor performance. Ten animals per group were initially trained to balance on a rotarod $($ a $15-\mathrm{cm}$ rotating drum which accelerated linearly from an initial speed of $4 \mathrm{rpm}$ ) until they fell onto a platform $30 \mathrm{~cm}$ below. Depression of the platform activated a switch halting the drum and a digital timer. The apparatus and procedure have been described more fully by Siemens and Doyle (1979). The animals were initially given five tests per day until they reached a stable level of performance ( $10 \%$ variation in performance on 3 consecutive days). After performance had stabilized ( 5 days of training), the rats were injected (IP) with test doses of ethanol or saline. The animals received two ethanol injections per week, generally separated by 72 or $96 \mathrm{~h}$. Since older and younger animals differed appreciably in their nondrug performance levels (46 $\pm 6 \mathrm{sec}$ for older rats vs. $101 \pm 14 \mathrm{sec}$ for younger), the effects of each dose of ethanol were expressed as a percentage of the mean of the saline injection trials on the day prior to and after drug injection. The rats were given three consecutive trials (separated by $30 \mathrm{sec}$ ) under each condition, and the score for each animal was the mean of these three trials.

Ethanol-induced hypothermia. Following a 2-h acclimation period to room temperature $\left(17.0^{\circ}-19.0^{\circ} \mathrm{C}\right)$, the animals $(\mathrm{N}=$ $10 /$ group) were injected (IP) every other day with 1,2 , or $3 \mathrm{~g} / \mathrm{kg}$ of ethanol $(10 \% \mathrm{w} / \mathrm{v})$. Rectal temperatures (Yellow Springs Telethermometer) were determined immediately prior to injection and at 45-min intervals thereafter.

\section{RESULTS}

\section{Ethanol Hypnosis}

The results are presented in Table 1 . The experiment was terminated at $9 \mathrm{~h}$ after injection of the $4.0 \mathrm{~g} / \mathrm{kg}$ dose of ethanol. Six of the 12 animals in Group $\mathrm{O}$ did not recover by this time (blood ethanol data from these animals were not included in the analysis). Ethanol hypnosis was shortest in the young animals, longer in the middle-age group, and of longest duration in the oldest animals $[\mathrm{F}(2,33)=34.7$, $\mathrm{p}<.01$ ]. Young animals "slept" for a significantly shorter period than the middle-age group [ $\mathrm{t}(22)=$ $5.35, \mathrm{p}<.01]$ and old animals $[\mathrm{t}(21)=7.64, \mathrm{p}<.01]$. Old rats slept significantly longer than the middle-

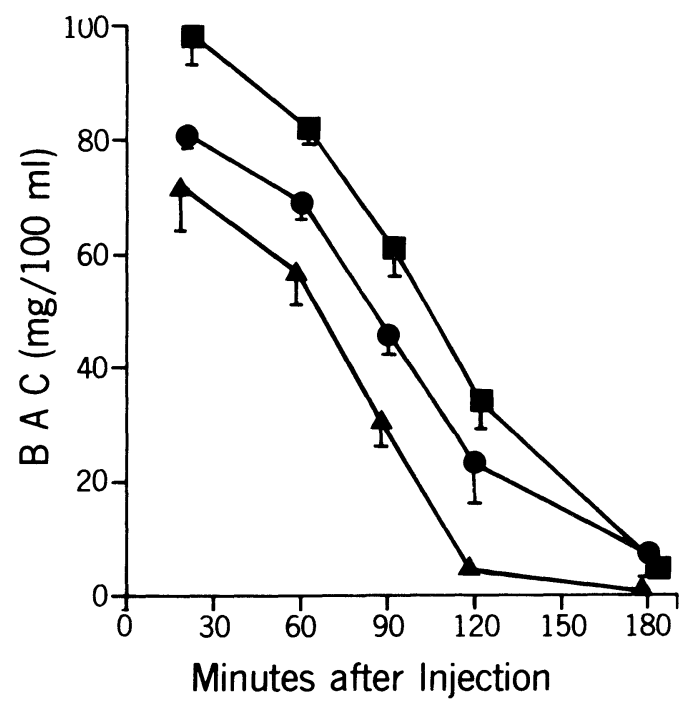

Figure 1. Disappearance of ethanol $(1.0 \mathrm{~g} / \mathrm{kg}$, IP) from the blood in young $(\Delta-\Delta, 2-3$ months), middle-age $(\bullet-\bullet$, 12-14 months), and old ( $\square, 18-20$ months) rats. $N=$ 10/group. Vertical lines refer to S.E.M. B.A.C. = blood alcohol concentration.

age group $[\mathrm{t}(21)=4.19, \mathrm{p}<.01]$. The blood alcohol levels at time of awakening, however, were in the opposite direction; the youngest animals had the highest blood alcohol concentrations and the oldest animals had the lowest blood alcohol concentration $[\mathrm{F}(2,27)=13.6, \mathrm{p}<.01]$. Blood alcohol levels at time of awakening were significantly higher for the young compared with both the middle-aged and oldest animals $[\mathrm{t}(22)=4.76$ and $\mathrm{t}(16)=4.17, \mathrm{p}<.01]$. $[\mathrm{t}(16)=.4]$. No statistically significant differences among groups were observed in the latency to the onset of hypnosis.

\section{Blood Ethanol Disappearance}

The data are presented in Figure 1. Blood ethanol concentrations were highest in the older rats, next highest in the middle-age group, and lowest in the young rats $[F(2,27)=11.8, p<.01]$. As testing continued, differences in blood ethanol were no lon-

Table 1

Ethanol Hypnosis in Rats of Different Ages

\begin{tabular}{|c|c|c|c|c|c|c|c|c|}
\hline \multirow[b]{2}{*}{ Age Group } & \multicolumn{2}{|c|}{$\begin{array}{c}\text { Weight } \\
\text { (in Grams) }\end{array}$} & \multicolumn{2}{|c|}{$\begin{array}{c}\text { Onset of } \\
\text { Hypnosis } \\
\text { (in Minutes) }\end{array}$} & \multicolumn{2}{|c|}{$\begin{array}{r}\text { Sleep Time } \\
\text { (in Minutes) }\end{array}$} & \multicolumn{2}{|c|}{$\begin{array}{l}\text { Blood Ethanol at } \\
\text { Waking (in Milli- } \\
\text { grams } / 100 \mathrm{ml} \text { ) }\end{array}$} \\
\hline & Mean & SE & Mean & SE & Mean & SE & Mean & $\mathrm{SE}$ \\
\hline Young (2-3 months) & 183 & 3 & 1.88 & .06 & 177 & 10 & 268 & 8 \\
\hline Middle (12-14 months) & 363 & 9 & 2.04 & .14 & 296 & 19 & 207 & 10 \\
\hline Old (18-20 months) & 441 & 23 & 2.07 & .09 & $>454$ & $36 *$ & 213 & 10 \\
\hline
\end{tabular}

Note-The number of animals studied was 12, with the exception that only six blood ethanol determinations were made on the older rats (see text for explanation). Female CD rats of different ages were injected (IP) with $4.0 \mathrm{~g} / \mathrm{kg}$ ethanol (20\% w/v). Sleep time refers to the time between loss and recovery of the righting reflex. Immediately after recovery of the righting reflex, tail-tip blood samples were taken and analyzed for ethanol concentrations.

*"Sleep time" for animals for which blood samples were taken = $384 \mathrm{~min}$ (SE = 50.7). 


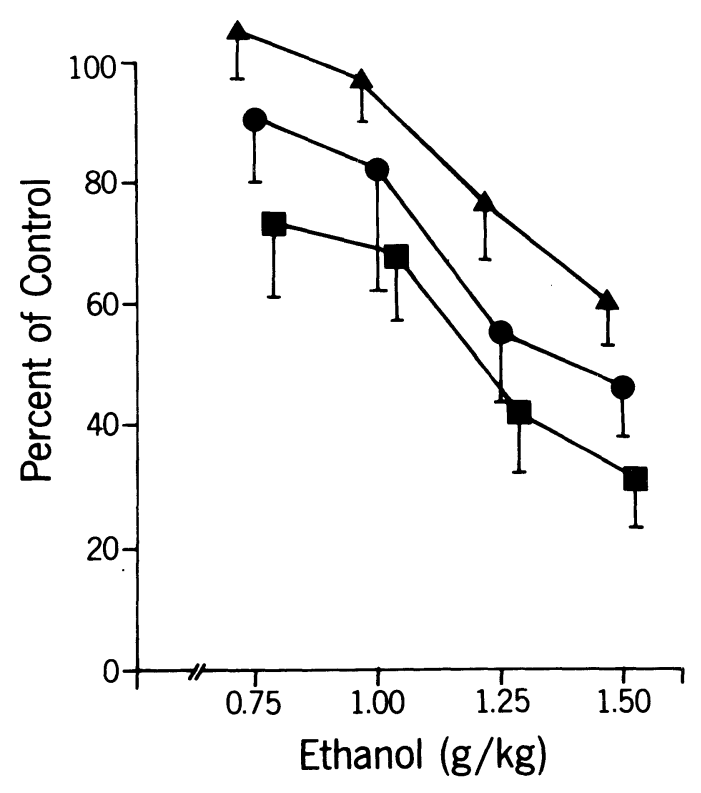

Figure 2. Motor impairment produced by various doses of ethanol in rats of different ages: $\Delta-\Delta$, young (2-3 months), $\bullet-\bullet$, middle (12-14 months), $\square$, old (18-20 months). The animals were injected (IP) with ethanol $(10 \% \mathrm{w} / \mathrm{v})$ or equivolume saline and tested 20 min later on the rotarod. Performance on the rotarod is expressed as a percent of the mean of the values obtained with saline on the day before and the day after the ethanol test (see text for details). $N=10 /$ group. Vertical lines refer to S.E.M.

ger different, as indicated by the significant Age by Time interaction $[F(8,108)=3.10, p<.01]$. Blood alcohol levels were significantly lower in young animals compared with the middle-aged and old animals $[\operatorname{ts}(18)=6.93$ and 22.4 , respectively; $\mathrm{p}<.01$ ] and in middle-aged compared with old animals $[\mathrm{F}(1,18)$ $=5.22, \mathrm{p}<.04]$. Group differences with respect to rate of disappearance of ethanol were not statistically significant.

\section{Impairment of Motor Performance by Ethanol}

The data are presented in Figure 2. Ethanol-induced impairment of performance on the rotarod was directly related to the age of the group studied for all doses of ethanol employed $[\mathrm{F}(2,27)=4.19, \mathrm{p}<.03]$. The oldest animals, but not the middle-aged animals, were significantly more impaired than younger animals at all doses $[\mathrm{F}(1,18)=12.41, \mathrm{p}<.01]$. Dose-related increments in impairment were observed with higher doses of ethanol. Differences between middle-aged and older animals were not statistically significant.

\section{Ethanol-Induced Hypothermia}

As indicated in Figure 3, the body temperature of the older rats was decreased to a much greater extent compared with that of the other groups by each of the doses of ethanol $[F(2,84)=9.93, p<.001]$. The body temperature of the older animals also took significantly longer to recover, as indicated by the Age by Time interaction $[\mathrm{F}(12,504)=4.72, \mathrm{p}<.001]$.

\section{DISCUSSION}

These data indicate that the effects produced by moderate to large doses of ethanol are more pronounced in old than in young rats. However, important differences may be involved in the mechanisms governing the different responses to ethanol measured in this study.

The more pronounced effects of lower doses of ethanol on motor performance and hypothermia in older vs. younger rats may be due entirely to the higher peak blood levels of ethanol achieved in those subjects with given doses of that drug. Inasmuch as ethanol in the blood equilibrates rather quickly with brain tissue (Wiberg et al., 1970), higher concentrations of ethanol in contact with critical target tissues would also be expected in older rats. This explana-
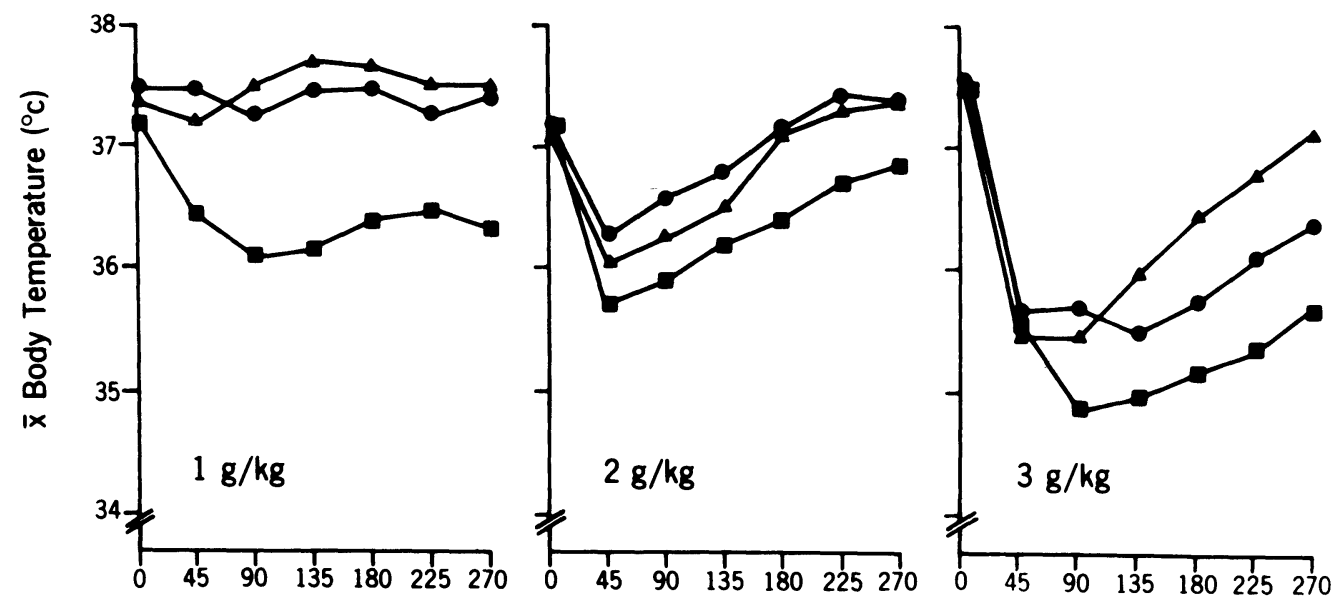

Minutes After Injection

Figure 3. Ethanol-induced hypothermia in rats of different ages: $\Delta-\Delta$ young (2-3 months), $-\longrightarrow$ middle (12-14 months), $\square$ old (18-20 months). Animals were injected (IP) with ethanol (10\% w/v) and tested at 45-min intervals thereafter. $N=10$ /group. 
tion derives, of course, from our data indicating that peak blood ethanol concentrations after injection of the $1-\mathrm{g} / \mathrm{kg}$ dose are higher in older vs. younger rats. Results comparable to the present study with respect to blood alcohol levels and disappearance have also been reported in the rat (Wiberg, Samson, Maxwell, Coldwell, \& Trenholm, 1971), following a $3-\mathrm{g} / \mathrm{kg}$ challenge dose, and in man (Vestal, McGuire, Tobin, Andres, Norris, \& Mezey, 1977), using a continuous infusion equivalent to a mean dose of $.57 \mathrm{~g} / \mathrm{kg}$.

The higher blood alcohol levels produced by injections of ethanol in older rats have been attributed to a smaller volume of distribution of ethanol in association with a lower body water content and decreased lean body mass in relation to total body mass in older rats (Wiberg et al., 1971; cf. also Vestal et al., 1977, for data in man). The greatest changes in body weight are observed between the young $(183 \pm 3 \mathrm{~g})$ and middle $(363 \pm 9 \mathrm{~g})$ age groups (Table 1). Wiberg et al. (1971) report even greater weight differences between male Wistar rats aged 3 and 12 months. A significant reduction in the ratio of lean body mass to total body mass was reported by those workers to accompany that age change. No significant change in body weight or in the ratio of fat to total body weight in male Sprague-Dawleys (Charles River CD) was found by Lesser, Deutsch, and Markofsky (1973) to occur after 12 months of age. Inasmuch as we observed a significant weight difference between the middle $(363 \pm 9 \mathrm{~g})$ and old $(441 \pm 23 \mathrm{~g})$ rats in our study, we feel it is not unreasonable to suggest that the trend toward a reduction in the ratio of lean body mass to total body mass also occurred in our middle and old rats. Thus, higher blood ethanol levels would be expected in older animals, since ethanol is distributed in accordance with total body water and is not appreciably distributed in body fat (Harger \& Hulpieu, 1956). This explanation, suggested by Wiberg et al. $(1970,1971)$ to account for the increased lethality (lower LD 50) in older (12-14 months) rats compared with younger (2-3 months) animals, is favored in the present study, although a slower rate of absorption in young rats allowing a greater "first pass" metabolism of ethanol by the liver cannot be entirely ruled out as a possible contributing factor.

Thus, the greater effects of moderate doses of ethanol in older rats may be due entirely to a higher concentration of ethanol in the blood and, presumably, at important target tissues. When doses are adjusted such that comparable blood concentrations of ethanol are achieved in young and old groups, the effects of ethanol are expected to be comparable. For example, a $1.5-\mathrm{g} / \mathrm{kg}$ dose of ethanol in younger rats produced impairment on the rotarod similar to that produced by the $1.0-\mathrm{g} / \mathrm{kg}$ dose in the older rats (see Figure 2 ). An analysis of the blood ethanol concentrations pro- duced by those doses revealed that the blood levels achieved in young $(114.1 \pm 7.9 \mathrm{mg} / 100 \mathrm{ml})$ and old $(99.1 \pm 3.0 \mathrm{mg} / 100 \mathrm{ml})$ animals were not significantly different $(\mathrm{p}>.05)$.

The reasoning involved in the interpretation of the hypnosis data is somewhat different. Following injection of the $4.0-\mathrm{g} / \mathrm{kg}$ dose of ethanol, older animals slept longer than younger subjects. Higher peak blood levels of ethanol in older subjects probably contributed to that effect. However, the finding that blood (and presumably, brain) ethanol levels at the time of awakening were lower in older animals suggests that the neural tissue involved in hypnosis is more affected by ethanol in those animals or, alternatively, the development of acute tolerance (i.e., the adaptive changes that develop during a single exposure to ethanol) is greater in younger animals. In other words, less ethanol in contact with critical brain tissue was necessary to maintain hypnosis in old vs. young subjects. We have no evidence that such a mechanism plays a role in the response to smaller doses of ethanol. Further studies will be necessary to determine which of these explanations (i.e., sensitivity vs. acute tolerance) should be favored in the interpretation of the hypnosis data.

\section{REFERENCES}

Abel, E. L. Effects of ethanol and pentobarbital in mice of different ages. Physiological Psychology, 1978, 6, 366-368.

Barnes, G. M., \& Russell, M. Drinking patterns among adults in western New York state: $A$ description analysis of the sociodemographic correlates of drinking. Buffalo: Research Institute on Alcoholism, 1977.

Cahalan, D., \& Cisin, I. H. American drinking practices: Summary of findings from a national probability sample. I. Extent of drinking by population subgroups. Quarterly Journal of Studies on Alcohol, 1968, 29, 130-151.

Epstein, L. J., Mills, C., \& Simon, A. Antisocial behavior of the elderly. California Mental Health Research Digest, 1970, 8, 78-79.

Greizerstein, H. B., \& Smith, C. M. Development and loss of tolerance to ethanol in goldfish. Journal of Pharmacology and Experimental Therapeutics, 1973, 187, 391-399.

Harger, R. N., \& Hulpieu, H. R. The pharmacology of alcoholism. In G. N. Thompson (Ed.), Alcoholism. Springfield, Ill: Thomas, 1956.

Lesser, G. T., Deutsch, S. A., \& Markofsky, J. Aging in the rat: Longitudinal and cross-sectional studies of body composition. American Journal of Physiology, 1973, 225, 1472-1478.

Petersen, D. M., \& Whittington, F. J. Drug use among the elderly: A review. Journal of Psychedelic Drugs, 1977, 9, 25-37.

Samorajski, T., Strong, J. R., \& Sun, A. Y. Dehydroergotoxine (hydergine) and alcohol-induced variations in young and old mice. Journal of Gerontology, 1977, 32, 145-152.

Schuckit, M. A., \& Miller, P. L. Alcoholism in elderly men: A survey of a general medical ward. Annals of the New York Academy of Sciences, 1976, 273, 558-571.

Schuckit, M. A., \& PAstor, P. A., JR. The elderly as a unique population: Alcoholism. Alcoholism: Clinical and Experimental Research, 1978, 2, 31-38.

Siemens, A. J., \& Doyle, O. Cross-tolerance between $\Delta^{9}$-tetra- 
hydrocannabinol and ethanol: The role of drug disposition. Pharmacology, Biochemistry and Behavior, 1979, 10, 49-55.

Sun, A. Y., \& Samorajski, T. The effects of age and alcohol on $\left(\mathrm{Na}^{+}+\mathrm{K}^{+}\right)$-ATPhase activity of whole homogenate and synaptosomes prepared from mouse and human brain. Journal of Neurochemistry, 1975, 24, 161-164.

Vestal, R. E., McGuire, E. A., Tobin, J. D., Andres, R., Norris, A. H., \& Mezey, E. Aging and ethanol metabolism. Clinical Pharmacology and Therapeutics, 1977, 21, 343-354.

Wilberg, G. S., Samson, J. M., Maxwell, W. B., Coldwell, B. B., \& Trenholm, H. L. Further studies on the acute toxicity of ethanol in young and old rats: Relative importance of pulmonary excretion and total body water. Toxicology and Applied Pharmacology, 1971, 20, 22-29.

Wiberg, G. S., Trenholm, H. L., \& Coldwell, B. B. Increased ethanol toxicity in old rats: Changes in LD50, in vivo and in vitro metabolism, and liver alcohol dehydrogenase activity. Toxicology and Applied Pharmacology, 1970, 16, 718-727.

Zimberg, S. The elderly alcoholic. Gerontologist, 1974, 14, 221-224.

(Received for publication August 2, 1979; accepted October 9, 1979.) 